\title{
Homenaje a Roberto Innocenti: Un ilustrador de su tiempo'
}

\section{Homage to Roberto Innocenti: an Illustrator of his Time}

\author{
MARÍA JOSÉ FERRADA \\ Chile \\ mariajose.ferrada@gmail.com
}

(Recibido 29-II-2OI3;

aceptado O2-I2-2OI3)

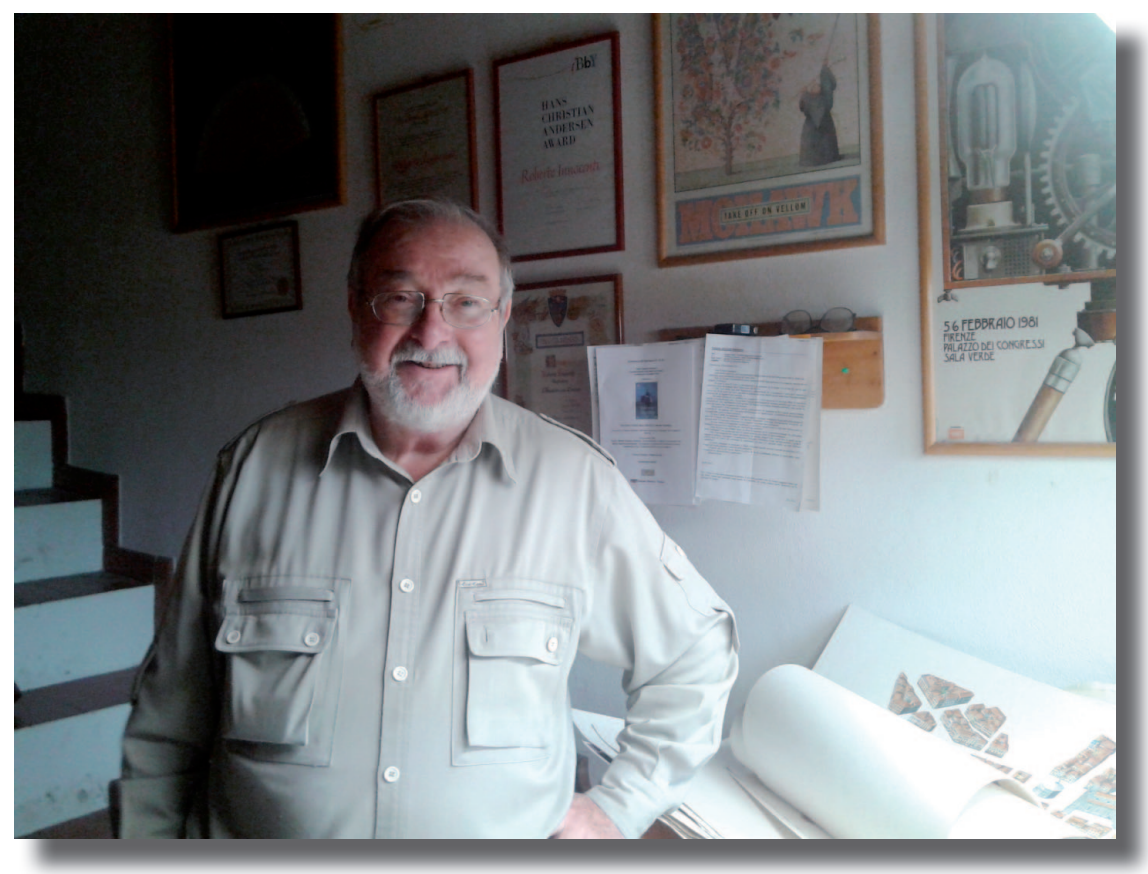

Roberto Innocenti (Bagno a Ripoli, I940) es uno de los ilustradores más importantes de la actualidad, reconocido con los máximos galardones que hay para su oficio, entre los que se cuenta el premio Hans Christian Andersen en el año 2008. Su obra, que ha sido traducida a lenguas tan diversas como el chino, el japonés y el georgiano, ha llegado hasta los hispanohablantes gracias a la editorial Kalandraka, Historia de Erika (2005); Las aventuras de Pinocho (2008); La casa (20IO); Canción de Navidad (20II), La niña de rojo (20I3), a Fondo de Cultura Económica, El último Refugio (2003) y a Lóguez, Rosablanca (1987).

I Para citar este artículo: Ferrada, María José (20I3). Homenaje a Roberto Innocenti: Un ilustrador de su tiempo. Alabe 8 [www.revistaalabe.com] 
Sí, Roberto Innocenti es uno de los ilustradores más importantes de la actualidad, pero también es un defensor de la libertad, un guardián de la memoria, un crítico de su época y tal vez uno de los últimos bastiones de una forma de hacer ilustración en la que la técnica, que maneja como pocos, está al servicio de una forma de entender y de pensar el mundo que le tocó habitar.

Lo conocí a fines de marzo de 20I3, cuando en compañía de sus editores españoles, fuimos hasta su casa, en las afueras de Florencia con el objetivo de conocer su trabajo más de cerca y hacerle algunas preguntas sobre su forma de entender el oficio. Ahí estaba el gran Roberto Innocenti, afable y sencillo, esperándonos en medio de un paisaje que así como la mayoría de sus seguidores, ya habíamos recorrido en obras como La casa o esa entrañable versión del niño de madera que gracias a su pincel, se convertiría en un niño tan claro y tan oscuro como cualquier otro que habitara las grandezas y penurias del siglo XX.

Y es que en el tiempo del detalle, en esa pausa que es requisito de la mirada aguda, parece tener cabida toda la luz y también toda la sombra de un siglo y de la humanidad entera. Ciertos artistas nos han permitido mirar a través de esa fisura que atraviesa el mundo. Roberto Innocenti es uno de ellos. Lo primero que llama mi atención son los estantes de libros. Geografía, teoría política, historia. Imagino a Inoccenti intentando conocer y comprender a ese extraño animal que es el ser humano, para recién entonces dibujarlo.

Lo primero que nos dice es que la ilustración es ante todo una forma de comunicar una visión de la vida. Pero el decir requiere de un territorio de libertad por el que transitar, un camino que no siempre es un sendero llano. Por lo mismo, los comienzos no serían fáciles y su obra como ilustrador, que comienza a hacerse notar en la década de los 8o, encontraría en el extranjero la acogida que le sería esquiva en su Italia natal, esa que a pesar de todo, no se cansa de retratar.

Leo en las entrevistas con las que preparo mi visita, que en su carrera profesional hubo dos nombres claves: John Alcorn y Étienne Delessert. El primero de ellos que llegó a Italia en la década de los 7o, tenía un estudio de ilustración en Nueva York y trabajaba para L'Espresso. Innocenti por su parte, sobrevivía haciendo manifiestos, dibujando objetos, en una Italia en la que recuerda que era imposible sobrevivir del oficio.

Pero la dificultad se transforma a sus ojos en ventaja: "Era en el fondo más divertido, se hacía más experiencia, al tener que diversificarte más. Era una escuela de vida, ya que tan pronto ilustrabas animales para revistas de caza y pesca como pasabas a otra cosa diametralmente distinta. Gracias a esta experiencia descubrí que estaba maduro para la ilustración cuando empecé a practicarla, porque antes hacía de todo, pero no estaba seguro de saberlo hacer bien" (http://www.fabulantes.com/2OI2/o9/entrevista-a-roberto-innocenti-ilustrador-i/) 
En la misma entrevista, cuenta que sería Alcorn quien a su regreso a Estados Unidos presentaría su trabajo a Delesert, editor que le encargaría su primer trabajo autoral: La Cenicienta, que retrataría en una versión de los años 20 , cuyo escenario, pre depresión de los años 3o, se ajustaría según la mirada del autor, a la frivolidad de la historia original: una chica que sueña casarse con un príncipe.

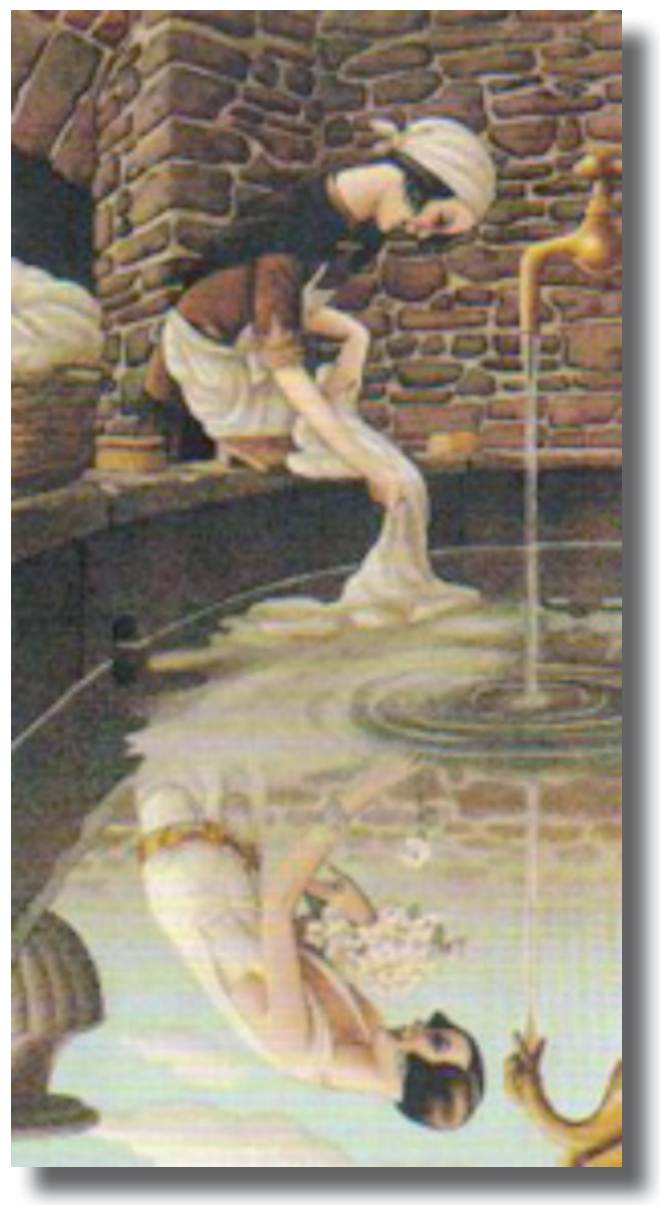

A ese primer libro de autor con el que Innocenti ganaría a la industria un espacio de libertad, seguiría Rosa Blanca (I985; versión española de Lóguez Ediciones, 1987), obra que presenta una de las temáticas en torno a la que girará parte importante de su producción: el siglo XX y sus heridas. Porque Rosa Blanca, la pequeña protagonista -cuyo nombre hace alusión al grupo de mujeres pacifistas que levantaría la voz en contra el nazismo pagando la osadía con la muerte- es también una pequeña víctima de esa grieta irreparable en la historia de la humanidad.

La pequeña Rosa Blanca al ver invadida su aldea por las tropas y los vehículos militares se preguntará hacia dónde marchan esos camiones, qué transportan. Y su curiosidad la llevará a seguirlos. Sabemos de qué se trataba. Sabemos qué era, quiénes eran. Sabemos que lo que llevaban esos camiones no era otra cosa que el horror. Las tropas abandonan la aldea, pero antes suena un último disparo. En tiempos de guerra el enemigo está en todas partes, también en los niños inocentes.

Roberto Innocenti detiene su mirada, su pincel realista para no permitirnos el olvido y para que los niños y niñas que conozcan la historia se encarguen de que ésta no vuelva a repetirse.

El artista es también el constructor de la memoria. En títulos como La historia de Erika o La casa, volveremos a mirar y pensar, la guerra. Agradecemos a Inoccenti porque al estremecernos, imaginamos su propio estremecimiento, el dolor de quien tiene la valentía para mirar su tiempo así, sin velo. 
¿Libros para niños? Sí, para quien entiende que niñez e inocencia no son sinónimos de debilidad. Porque Innocenti invita a los niños y niñas a entrar a ese pequeño museo que son sus libros para que al salir ya no sean los mismos. Y tal vez sea así porque los respeta.

Imposible abordar en estas páginas la profundidad de su obra. Solo diremos que al finalizar El Último Refugio, ese al que llegan los personajes de los cuentos, buscando el sentido perdido; Las Aventuras de Pinoccho, el niño de madera que deambula inocente y destructivo por el paisaje toscano, buscando qué otra cosa sino la propia infancia, o La niña de rojo, esa caperucita que atraviesa los peligros de la selva de cemento, tampoco nosotros somos los mismos. Los clásicos tienen esa función: alumbrar espacios de nuestra humanidad, antes desconocidos. Y Roberto Innocenti, con su mirada centrada en el detalle, esa en la que lo pequeño habla para mostrarnos lo profundo, se ha convertido en uno.

Le preguntamos por su oficio. Le pedimos un consejo para los jóvenes ilustradores que siguen el camino que él ha transitado y nos contesta generoso pero no por eso menos crítico. Innocenti comenta que los tiempos donde la felicidad es sinónimo de consumo, son tiempos de crisis.

"A un joven ilustrador le diría que a dibujar se aprende dibujando y que es fundamental tener ganas de contar una historia. Porque ilustrar es comunicar y para comunicar hay que mirar el mundo, estar con los ojos abiertos. Mirar muchos libros sí, pero no para copiar, sino para ver qué quieren decir otros y cómo lo dicen. Cada país tiene sus características propias, pero es importante no quedarse encerrado en eso, porque el texto va traducido, pero la ilustración debe ser capaz de hablar, de comunicar, a personas que están fuera de ese pequeño círculo que es el nuestro. Y le diría por último, que después de dibujar y dibujar, no basta con saber dibujar, hay que conocer, aprender siempre, porque para comunicar hay que tener algo que decir. Hay que forjar un mundo interior rico y luego, intentar volcar eso en el papel”.

Y es que Roberto Innocenti ha logrado no un estilo sino una mirada, y no cualquier mirada sino que una en la que el mundo logra reflejarse. Desde sus ojos el mundo y su tiempo nos miran. Y sus lectores, agradecidos, nos miramos en él. 


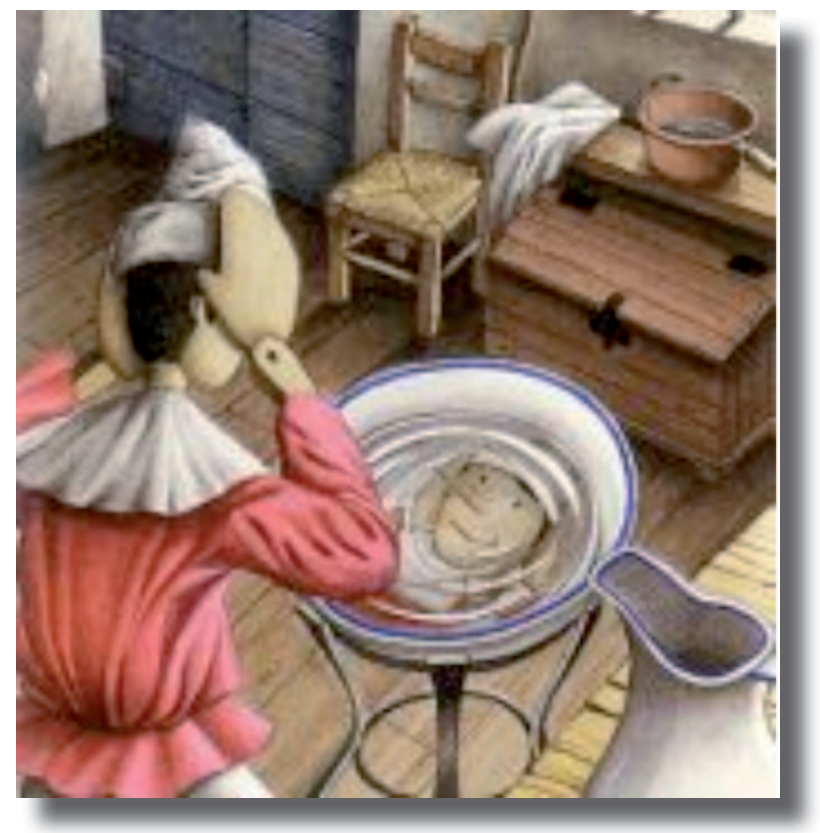

\section{Referencias}

- Collodi, Carlo e Innocenti, Roberto (2008). Las aventuras de Pinocho. Sevilla: Kalandraka.

- Dickens, Charles e Innocenti, Roberto (2OII). Canción de Navidad. Sevilla: Kalandraka.

- Gallaz, Christophe e Innocenti, Roberto (I987). Rosa Blanca. Salamanca: Lóguez Ediciones.

- Innocenti, Roberto y Aaron Frisch (20I3). La niña de rojo. Sevilla: Kalandraka.

- Lewis, J. Patrick e Innocenti, Roberto (2003). El último refugio. México: Fondo de Cultura Económica.

- Lewis, J. Patrick e Innocenti, Roberto (2OIO). La casa. Sevilla: Kalandraka.

- Torán, Joaquín (2OI2). Entrevista a Roberto Innocenti, ilustrador. (http://www.fabulantes.com/20I2/og/entrevista-a-roberto-innocenti-ilustrador-i/)

- Vander Zee, Ruth e Innocenti, Roberto (2005) Historia de Erika. Pontevedra: Kalandraka. 